\title{
RETOS DE LA REGULACIÓN JURÍDICO- PENAL DE LA MINERÍA EN COLOMBIA. ESTUDIO DEL ARTÍCULO 333 DEL Código PENAL COLOMBiano*
}

\author{
CHALLENGES OF CRIMINAL-LAW \\ REGULATION OF MINING IN COLOMBIA. \\ A STUDY OF THE ARTICLE 333 OF \\ THE COLOMBIAN CRIMINAL CODE
}

Beatriz Eugenia Suárez-López***

Fecha de recepción: 6 de marzo de 2017

Fecha de aceptación: 20 de marzo de 2017 Disponible en linea: 30 de noviembre de 2017

\section{Para citar este artículo/To cite this article}

Suárez-López, Beatriz Eugenia, Retos de la regulación jurídico-penal de la minería en Colombia. Estudio del artículo 333 del Código Penal colombiano, 135 Vniversitas, 421-456 (2017). https://doi.org/10.11144/Javeriana. vj135.rrjp doi:10.11144/Javeriana.vj135.rrjp

* Artículo basado en la ponencia presentada en el XIX Seminario Interuniversitario Internacional de Derecho Penal, Derecho Penal General y Derecho Penal de la Empresa, en la Universidad de Alcalá de Henares, España, el 2 y 3 de junio de 2016.

** Abogada, Universidad Externado de Colombia, ORCID: http://orcid.org/0000-0003-1237-3085. Especialista en ciencias penales y criminológicas de la misma universidad. Máster en derecho con especialidad en derecho penal en la modalidad investigadora y doctoranda en derecho penal, Universidad Alcalá de Henares. Profesora asociada, Universidad de Bogotá Jorge Tadeo Lozano. Contacto: beatrize.suarezl@utadeo.edu.co 


\section{RESUMEN}

Este artículo aborda el estudio del artículo 333 del Código Penal (CP) colombiano que establece el delito de contaminación ambiental por explotación de yacimiento minero o hidrocarburo, analiza su redacción y los efectos penales que de él se derivan, con énfasis en las dificultades del delito desde el punto de vista del principio de legalidad, pero también aborda algunos problemas dogmáticos. Este artículo hace parte de los resultados de la investigación Derecho penal ambiental en el contexto de la empresa. Problemas en torno al delito de contaminación ambiental, financiada por la Universidad de Bogotá Jorge Tadeo Lozano.

Palabras clave: Contaminación ambiental; minería ilegal; delitos contra el medio ambiente; medio ambiente 


\section{ABSTRACT}

This paper presents a study of the article 333 of the Colombian Criminal Code, which establishes the crime of environmental contamination by exploitation of mining or hydrocarbon deposits. It analyzes the semantics and scope of this rule, establishing the criminal effects deriving from it. The paper focuses on the challenges that the article poses for the principle of legality, and address some dogmatic problems of it. This paper is part of the results of the research Environmental Criminal Law in the Context of the Company. Problems Surrounding the Crime of Environmental Pollution, supported by Universidad de Bogotá Jorge Tadeo Lozano.

Keywords: Environmental pollution; illegal mining; crimes against the environment; environment

\section{SUMARIO}

Introducción.- I. Minería, Medio AMBiente y DeReCho PENAL.- II. Bien JURÍDICO PROTEGIDO POR EL DELITO DE CONTAMINACIÓN AMBIENTAL POR EXPLOTACIÓN DE YACIMIENTO MINERO O HIDROCARBURO.- $A$. La norma.- $B$. Bien jurídico protegido.- III. Problemas en toRno al Delito.- $A$. Los verbos rectores y la posibilidad de comisión real del delito.- B. ¿Y las normas penales en blanco?- C. ¿Delito de peligro abstracto o de lesión?- CONCLUSIONES.- BIBLIOGRAFÍA. 


\section{INTRODUCCIÓN}

En las últimas décadas, el mundo ha sido testigo de un cambio de conciencia hacia el ambiente. Este ha dejado de ser visto como un mero instrumento en procura del bienestar de la humanidad y ha adquirido un papel mucho más protagónico en el escenario del crecimiento industrial y tecnológico. Ello ha generado que los asuntos ambientales pierdan su carácter doméstico, para empezar a ocupar las agendas de discusión de los Estados, en el entendimiento de que el deterioro ambiental traspasa fronteras y requiere la toma de acciones conjuntas para mitigar estos daños ${ }^{1}$.

Los primeros instrumentos adoptados internacionalmente pretendían poner en una balanza la protección del ambiente, por un lado, y los avances industriales, por el otro, con el fin de lograr el equilibrio perfecto entre estos dos, sin necesidad de limitarlos.

No obstante, este cometido se fue haciendo cada vez más utópico, pues la balanza necesariamente se inclinaba hacia alguno de los extremos $^{2}$. Este problema deja en evidencia que las acciones deben ser más consistentes y reales ${ }^{3}$.

Si bien todo lo anterior resulta importante, también es innegable que para los Estados los intereses económicos juegan un papel preponderante en la toma de decisiones y, por ello, en países como

1 Francisco Muñoz-Conde, María Carmen López-Peregrín \& Pastora García-Álvarez, Manual de derecho penal medioambiental, 25-26 (2ª ed., Tirant lo Blanch, 2015). Agustina Iglesias-Skulu, La protección de la ordenación del territorio, el patrimonio histórico y el medio ambiente en la sociedad del riesgo, en Ordenación del territorio, patrimonio histórico y medio ambiente en el Código Penal y la legislación especial, 19-34, 19 (PAtricia Faraldo-Cabana, dir., Tirant lo Blanch, Valencia, 2011). Álvaro Mendo-Estrella, El delito ecológico del artículo 325.1 del Código Penal, 20-21 (Tirant lo Blanch, Valencia, 2009).

2 En ese sentido, podría decirse que la Declaración de Estocolmo de 1972 (primer instrumento de la Naciones Unidas que se refiere de manera exclusiva a la protección del ambiente) establece una serie de principios con una visión muy idealista. Organización de Naciones Unidas, Conferencia de las Naciones Unidas sobre el Medio Humano, A/CONF.48/14/Rev.1, Declaración de Estocolmo, 5-16 de junio de 1972. Disponible en: http:/www.un.org/es/comun/docs/?symbol=A/CONF.48/14/ Rev.1. De otro lado, la Declaración de Río de 1992 aterriza mejor los principios anteriores y desarrolla conceptos para una aplicación más real. Organización de Naciones Unidas, Conferencia de las Naciones Unidas sobre el Medio Ambiente y el Desarrollo, A/CONF.151/26 (Vol. I), Declaración de Río, 3-14 de junio de 1992. Disponible en: http:/www.un.org/documents/ga/conf151/spanish/ aconf15126-1annex1s.htm

3 Esta pretendida eficacia ha llevado a plantearse principios que han de estar presentes en el desarrollo de actividades que puedan generar impactos ambientales, como el principio de desarrollo sostenible, o el principio de responsabilidad intergeneracional en el manejo adecuado de los recursos, los cuales han de ser tenidos en cuenta para el desarrollo de políticas ambientales por parte de los Estados y, además, por parte de las empresas. Cfr. Declaración de Río de 1992. 
Colombia, con grandes riquezas naturales y diversos recursos a explotar, el Estado ve en ello una oportunidad en términos económicos que no puede desaprovechar y por tanto, actividades que se han catalogado como de gran impacto contra el ambiente - como la minería - vienen a ser propiciadas por el Estado aun cuando en su puesta en marcha los deterioros ambientales pretendan ser aminorados. Teniendo lo anterior como un punto de partida, el presente artículo identifica estos problemas y los aborda desde la perspectiva del derecho penal.

Este artículo es uno de los resultados obtenidos en el desarrollo del proyecto de investigación Derecho penal ambiental en el contexto de la empresa. Problemas en torno al delito de contaminación ambiental, financiado por la Universidad de Bogotá Jorge Tadeo Lozano, el cual tenía como objetivo general identificar los problemas dogmáticos y de políticas criminales en relación con el delito de contaminación ambiental en Colombia, para lo cual se decidió no solo ceñirse al estudio del delito ecológico básico, esto es el establecido en el artículo 332 del Código Penal (CP) colombiano ${ }^{4}$, sino que el análisis se extendió a otras figuras delictivas como el delito de contaminación ambiental por explotación de yacimiento minero o hidrocarburo tipificado en el artículo 333 del mismo instrumento normativo.

Este trabajo realizará entonces una aproximación a la problemática de la persecución penal en contra de la minería ilegal bajo estas figuras delictivas, con énfasis en el delito de contaminación ambiental por explotación de yacimiento minero e hidrocarburo, para lo cual se han identificado los inconvenientes que dicha norma presenta al momento de ser implementada, los cuales han sido agrupados en: primero, una aparente indebida técnica legislativa; y segundo, las dificultades dogmáticas que se derivan de la norma.

Así, la primera parte de este artículo buscará acercarse a la situación de la minería en Colombia en cuanto a los efectos que el desarrollo de esta actividad genera en el medio ambiente, para intentar explicar por qué se acude al Derecho penal para proteger el bien jurídico ambiental. Seguidamente, se abordará el concepto de bien jurídico-penal medio ambiente. En una tercera parte se es- 
tudiará el delito consagrado en el artículo 333 al identificar las principales modificaciones introducidas por la Ley 1453 de $2011^{5}$ y los problemas legislativos y dogmáticos derivados de dichos cambios.

Este estudio parte de un enfoque multidisciplinar, en donde si bien los principales desarrollos se hacen a partir de la disciplina jurídica también se toman conceptos básicos utilizados en otras, como la filosofía, biología o ecología. La metodología utilizada consistió en la revisión de fuentes primarias y secundarias del derecho, tanto penal, constitucional y administrativo, los cuales fueron analizados extrayendo conclusiones hacia el campo de la aplicación efectiva del Derecho penal. Igualmente, se analizó la posición jurisprudencial de la Corte Suprema de Justicia, Sala de Casación Penal, en relación con el delito de contaminación ambiental.

\section{MINERÍA, MEDIO AMBIENTE Y DERECHO PENAL}

El ejercicio de la actividad minera no está exento de polémica. Por un lado, están sus efectos adversos sobre el medio ambiente y el ecosistema y, por otro, los intereses económicos presentes en la explotación minera. Estos factores inciden en la puesta en marcha de la actividad minera. De hecho, se ha llegado a afirmar que hay una gran incompatibilidad entre la protección del ambiente y la minería, pues su sola ejecución genera impactos negativos en los recursos naturales, que son tan solo uno de los factores que se ven afectados directamente por ella ${ }^{6}$.

5 Colombia, Ley 1453 de 2011, por medio de la cual se reforma el Código Penal, el Código de Procedimiento Penal, el Código de Infancia y Adolescencia, las reglas sobre extinción de dominio y se dictan otras disposiciones en materia de seguridad, 48.110 Diario Oficial, 24 de junio de 2011. Disponible en: http://www.secretariasenado.gov.co/senado/basedoc/ley_1453_2011.html

6 Al respecto: "La implementación del modelo extractivista de los recursos naturales no renovables, impulsado por los últimos gobiernos, se ha concretado en gran medida en la proliferación de títulos mineros y, de manera consecuente, en el incremento de actividades mineras en gran parte del territorio nacional. Esta situación ha llevado a que se privilegien estas actividades extractivas por parte de diferentes entidades del Estado sobre otro tipo de actividades productivas, e incluso sobre los derechos fundamentales y colectivos de los colombianos, lo que ha convertido a la minería en una actividad generadora de conflictos sociales, ambientales, económicos y culturales en varias regiones del territorio nacional". Rodrigo E. Negrete-Montes, Derechos, minería y conflictos. Aspectos normativos, en Minería en Colombia: derechos, políticas públicas y gobernanza, 23-56, 23 (LuIS Jorge Garay-Salamanca, dir., Contraloría General de la República, Bogotá, 2013). Disponible en: https://redjusticiaambientalcolombia.files.wordpress.com/2013/12/libro_mineria_contraloria-2013. pdf 
Sin ánimo de exhaustividad, pues no es el objeto principal de este estudio, pero sí con el propósito de poner de presente las distintas incidencias que se derivan de la actividad minera en Colombia, es preciso hacer mención de algunos estudios que las analizan desde diversas perspectivas políticas, económicas, sociales, culturales y, por supuesto, jurídicas. Todos estos aspectos no pueden entenderse de manera aislada; al contrario, es necesario apreciarlos en su conjunto para observar con mayor claridad este complicado panora$\mathrm{ma}^{7}$. Por otra parte, es necesario señalar que también hay estudios que avalan el ejercicio de la minería en el país, al considerar que priman más los aspectos positivos que los negativos ${ }^{8}$. Los principales argumentos a favor de la minería son aquellos que hacen énfasis en los ingresos económicos que percibe el Estado por concepto de impuestos y regalías, y también los beneficios sociales a favor de las comunidades locales 9 . Empero, la realidad es que esta inversión no es tan contundente en comparación con otros recaudos tributarios

7 Destacan Luis Jorge Garay-Salamanca (dir.), Mauricio Cabrera-Leal, Jorge Enrique Espitia-Zamora, Julio Fierro-Morales, Rodrigo E. Negrete-Montes, Luis Álvaro Pardo-Becerra, Guillermo Rudas-Lleras \& Fernando Vargas-Valencia, Minería en Colombia: derechos, políticas públicas y gobernanza (Contraloría General de la República, Bogotá, 2013). Disponible en: https://redjusticia ambientalcolombia.files.wordpress.com/2013/12/libro_mineria_contraloria-2013.pdf. GuILLERMO Rudas-Lleras, Daniel Hawkins \& Centro de Investigación y Educación Popular, CINEP, Programa por la Paz, La minería de carbón a gran escala en Colombia: impactos económicos, sociales, laborales, ambientales y territoriales (Friedrich-Ebert-Stiftung, FES, Bogotá, 2014). Disponible en: http:// library.fes.de/pdf-files/bueros/kolumbien/11067.pdf. Astrid Martínez-OrTiz (dir.), Minería y medio ambiente en Colombia (Centro de Investigación Económica y Social, Fedesarrollo, Sector de Minería a Gran Escala, SMGE, Bogotá, 2014). Disponible en: http://www.fedesarrollo.org.co/wp-content/ uploads/Fedesarrollo-Informe-Miner\%C3\%ADa-y-medio-Ambiente-final-final-final-080714.pdf. Centro de Investigación y Educación Popular, CINEP, Programa por la Paz, Minería, conflictos sociales y violación de derechos humanos en Colombia, Segundo Informe especial (Centro de Investigación y Educación Popular, CINEP, Bogotá, 2012). Disponible en: http://www.alainet.org/ images/IE_CINEP_octubre_2012.pdf

8 Llama la atención el documento Politica minera de Colombia. Bases para la minería del futuro, emitido por el Ministerio de Minas y Energía, en que se hacen afirmaciones como: “Además, la minería tiene impactos positivos importantes sobre diversas comunidades, pueblos indígenas, comunidades negras o afrocolombianas, raizales y gitanos, asentadas en el área de influencia de los proyectos mineros tanto existentes como potenciales. Algunas de estas comunidades han ejercido la minería como medio de sustento por generaciones". Ministerio de Minas y Energía, Política minera de Colombia. Bases para la minería del futuro, 9 (República de Colombia, Bogotá, 2016). Disponible en: https://www.minminas.gov.co/documents/10180/698204/Pol\%C3\%ADtica+Minera + de + Colombia+final.pdf/c7b3fcad-76da-41ca-8b11-2b82c0671320

9 Para algunos, la actividad minera es vista como un "mal necesario". Astrid Martínez-Ortiz (dir.), Minería y medio ambiente en Colombia, 6 (Centro de Investigación Económica y Social, Fedesarro1lo, Sector de Minería a Gran Escala, SMGE, Bogotá, 2014). Esta situación hace que muchas veces se acepten los efectos devastadores contra el ambiente a cambio del bienestar que se deriva de esa actividad; sin embargo, esta posición es demasiado conformista e insostenible a largo plazo. 
que se hacen en otras regiones por pago de impuestos ${ }^{10}$. Y, además, los programas derivados de la responsabilidad social empresarial son muy limitados pues no abarcan a toda la población o bien, en múltiples ocasiones, se planean y ejecutan tardíamente, sin contar con las verdaderas necesidades de la comunidad ${ }^{11}$.

En general, muchos problemas se derivan de la actividad minera, pero la política del Estado colombiano parece ir en dirección a mantenerla, aunque se intenta aplicar un concepto de "minería sostenible" que hace referencia al control que ha de ejercer el Esta$\mathrm{do}^{12}$. De hecho, estas son las principales conclusiones de los estudios sobre impacto ambiental de la minería en Colombia, en el entendido de que, si no puede evitarse el desarrollo de esta actividad, por las razones que se pretendan hacer valer, al menos han de crearse mecanismos para mitigar sus impactos. Esto ha sido recalcado por la Corte Constitucional colombiana; por ejemplo, en la sentencia C-389-16, indica que: "aunque la minería es una actividad permitida por el ordenamiento, y promovida por razones políticas, esta debe adelantarse dentro de un marco constitucional que responda adecuadamente a los mandatos descritos y a las tensiones con otros principios constitucionales, dentro de los estándares más altos de

10 Al respecto, es preciso indicar que "los municipios que, sin ser capitales de departamento, tienen un sector productivo no extractivo más consolidado, reciben por concepto de impuesto de industria y comercio per cápita más de cuatro veces lo recaudado por el mismo concepto por aquellos municipios de la Guajira y Cesar donde se concentra la extracción de carbón para exportación". Guillermo Rudas-Lleras, Notas sobre la minería de carbón a gran escala en Colombia, en La minería de carbón a gran escala en Colombia: impactos económicos, sociales, laborales, ambientales $y$ territoriales, 5-22 (Friedrich-Ebert-Stiftung, FES, Bogotá, 2014).

11 Cfr. Astrid Martínez-Ortiz (dir.), Minería y medio ambiente en Colombia (Centro de Investigación Económica y Social, Fedesarrollo, Sector de Minería a Gran Escala, SMGE, Bogotá, 2014). Esta publicación aborda con especial cuidado la relación de la actividad minera y la percepción de la comunidad. La actividad minera genera un rechazo por parte de la comunidad, ya que sus efectos negativos sobre el ambiente son palpables y las consecuencias nocivas para la comunidad más cercana también. Por ello, por medio de programas de responsabilidad social empresarial o responsabilidad corporativa, se pretende cambiar la cara negativa de las empresas por una positiva con programas en beneficio de la comunidad. Entonces, por medio de ellos, mitigan el impacto de sus actuaciones y, a la vez, se ganan la confianza de la comunidad. En materia de minería, se empieza a manejar un concepto de "minería sostenible", compuesta por cuatro componentes: económico, de gobernanza, ambiental y social. En relación con este último "se espera que las operaciones mineras garanticen una distribución justa de los costos y beneficios, que se respeten los derechos humanos y que el agotamiento de los recursos naturales no afecte a las generaciones futuras". El problema de estos programas es que muchos no se diseñan atendiendo las necesidades propias de cada comunidad afectada y terminan siendo implementados mecánicamente, solo por cumplir el requisito.

12 Al respecto: Colombia, Ministerio de Minas y Energía, Unidad de Desarrollo Minero Energética, Plan nacional para el desarrollo minero, visión al año 2019 (Ministerio de Minas y Energía, Bogotá, 2006). Disponible en: http://www.upme.gov.co/docs/pndm_2019_final.pdf 
defensa del ambiente, los derechos de las comunidades y de las personas involucradas en ella"13.

Teniendo claro el panorama que dejan la actividad minera y la preocupación que genera, el Alto Tribunal establece la obligación de intervención del Estado colombiano en el control de su desarrollo $^{14}$. Para ello se exige, desde el ámbito administrativo, cumplir con el lleno de los requisitos para la explotación, que son, principalmente: estar en posesión de un título minero y, a su vez, obtener una licencia ambiental. Al parecer, estos requisitos son meramente formales y tienen como fin principal permitir que el Estado ejerza control sobre las empresas dedicadas a la minería para recaudar los impuestos establecidos ${ }^{15}$.

La forma de ejercer la minería ha llevado a que se realicen ciertas clasificaciones ${ }^{16}$. Para ello se hará referencia a las definiciones establecidas en el Glosario técnico minero ${ }^{17}$. Según este, se entiende por minería legal, la "amparada por un título minero, que es el acto administrativo escrito mediante el cual se otorga el derecho a explorar y explotar el suelo y el subsuelo mineros de propiedad nacional, según el Código de Minas. El título minero deberá estar inscrito en el Registro Minero Nacional".

La minería informal es aquella "constituida por las unidades de explotación pequeñas y medianas de propiedad individual y sin ningún tipo de registros contables", es decir, es ejercida por

13 Colombia, Corte Constitucional, Sentencia C-389-16, 27 de julio de 2016, magistrada ponente María Victoria Calle-Correa, Consideraciones, 36. Disponible en: http://www.corteconstitucional.gov.co/ relatoria/2016/C-389-16.htm

14 Colombia, Corte Constitucional, Sentencia C-389-16, 27 de julio de 2016, magistrada ponente María Victoria Calle-Correa, Consideraciones, 36.

15 Esta situación se agrava con la declaratoria de inexequibilidad de la Ley 1382 de 2010 (Colombia, Corte Constitucional, Sentencia C-366-11, 11 de mayo de 2011, magistrado ponente Luis Ernesto Vargas-Silva. http://www.corteconstitucional.gov.co/relatoria/2011/c-366-11.htm) que pretendía ser más proteccionista con el medio ambiente al ejercerse la actividad minera, pero al no contar con la consulta previa a las comunidades indígenas devino su inconstitucionalidad. Si bien la Corte intentó evitar los efectos adversos de esta declaratoria, al mantener la vigencia de la norma por dos años más, pasado este tiempo no se ha emitido nueva ley que reemplazara la declarada inconstitucional y queda entonces vigente tan solo el Código de Minas, el cual es claramente mucho menos garantista. Colombia, Ley 685 de 2001, por la cual se expide el Código de Minas y se dictan otras disposiciones, 44.545 Diario Oficial, 8 de septiembre de 2001. Disponible en: http://www.secretariasenado.gov. co/senado/basedoc/ley_0685_2001.html

16 Colombia, Decreto 2191 de 2003 , por el cual se adopta el glosario técnico minero, 45.273 Diario Oficial, 8 de agosto de 2003. Disponible en: http://www.alcaldiabogota.gov.co/sisjur/normas/Norma1. jsp? $\mathrm{i}=9198$

17 Se advierte desde ya que las mismas no tienen ninguna relevancia jurídica, pues finalmente lo importante para el Estado es que se cumplan los requisitos formales mencionados. 
pequeños mineros, de manera artesanal. Normalmente, se trata de personas que realizan la actividad minera de antaño, rústicamente y no con fines de explotación masiva, sino para la subsistencia ${ }^{18}$. Esta clase de minería es especialmente problemática, pues si bien su ejercicio genera impactos negativos, estos siempre serán de menor escala que los generados por las grandes empresas dedicadas a la explotación minera, pero, en todo caso, al ser ejercida de manera tan rústica, no se tiene en cuenta la preservación del ambiente, por lo que genera graves daños a los recursos naturales, además de que por su forma de constitución frecuentemente evade el pago de impuestos. Por todo lo anterior, el propósito del Estado es formalizar la actividad minera, para ejercer mayor seguimiento y control ${ }^{19}$; sin embargo, esto genera muchos costos para los mineros informales, lo que se traduce en desinterés en la formalización y se mantiene la ilegalidad de la actividad.

Por último, por minería ilegal se entiende la "desarrollada sin estar inscrita en el Registro Minero Nacional y, por lo tanto, sin título minero. Es la minería desarrollada de manera artesanal e informal, al margen de la ley. También incluye trabajos y obras de exploración sin título minero. Incluye minería amparada por un título minero, pero donde la extracción, o parte de ella, se realiza por fuera del área otorgada en la licencia". Como se puede advertir, la minería informal conlleva implícitamente el calificativo de ilegal, por tanto, toda actividad minera que no cuente con los requisitos formales para su funcionamiento deviene en ilegal.

De otro lado, la minería criminal hace referencia a la actividad minera ejercida por grupos organizados al margen de la ley. Es decir, esta clase de minería puede ser financiada, controlada y/o desarrollada por estos grupos. Al parecer, según lo ha manifestado el mismo Estado, se pretende centrar las labores de investigación y judicialización por delitos ambientales en el ejercicio de la actividad minera sobre estos grupos ${ }^{20}$.

18 Al respecto, fue emitido el Decreto Reglamentario 2715 de 2010. Colombia, Decreto Reglamentario 2715 de 2010, por el cual se reglamenta parcialmente la Ley 1382 de 2010, 47.784 Diario Oficial, 28 de julio de 2010. Disponible en: http://www.alcaldiabogota.gov.co/sisjur/normas/Norma1.jsp?i=40043

19 Colombia, Ministerio de Minas y Energía, Unidad de Desarrollo Minero Energética, Plan nacional para el desarrollo minero, visión al año 2019 (Ministerio de Minas y Energía, Bogotá, 2006).

20 Ministerio de Ambiente y Desarrollo Sostenible, Nueva estrategia contra minería criminal es un paso fundamental en la lucha contra este flagelo: Ministro Vallejo (31 de julio de 2015). Disponible en: http://www.minambiente.gov.co/index.php/component/content/article?id=1942:nueva-estrategia- 
Desde el Código Penal de $1980^{21}$, el legislador colombiano decidió elevar a bien jurídico penal el medio ambiente al establecer un único delito para cumplir este propósito (contaminación ambiental). Tras la entrada en vigor del Código Penal de 2001, el catálogo de delitos ha ido en aumento con las diferentes reformas a las que ha sido sometido el Código Penal. Tal vez la más significativa para el tema que se pretende abordar en este artículo es la reforma de la Ley 1453 de 2011, que no solo crea nuevos delitos, sino que aumenta considerablemente las penas de los existentes. Además, la redacción de estos tipos cambia pues se agregan nuevos elementos no previstos, sobre los cuales puede recaer la conducta y también se establecen nuevos verbos rectores. De acuerdo con el trámite surtido en el Congreso, específicamente en la Cámara de Representantes, se indicó que la reforma obedecía a la necesidad de darle a la Fiscalía General de la Nación las herramientas necesarias para adelantar los procesos investigativos contra quienes cometían los crímenes contra el medio ambiente $^{22}$. Sin embargo, no deja de ser preocupante que estas herramientas insistan en la creación de figuras delictivas y el aumento de penas, en lugar de buscar un fortalecimiento institucional del ente investigador, lo cual llevaría, en principio, a poder adelantar las investigaciones con mayor eficiencia y eficacia.

Ha de tenerse en cuenta además que esta reforma obedecía, en principio, a la necesidad de crear un Estatuto de Seguridad, en el que, específicamente en materia penal ambiental, se contemplaba la reforma al artículo $338 \mathrm{CP}$ (Explotación ilícita de yacimiento minero y otros materiales ${ }^{23}$. Con todo, en la medida en que fue debatida la reforma, se insertaron nuevos artículos, se propusieron reformas a los ya existentes, sin que hubiera una clara posición acerca de las razones que llevaron a generar estos cambios. De hecho, según se desprende de los debates surtidos en el Congreso, varios

contra-mineria-criminal-es-un-paso-fundamental-en-la-lucha-contra-este-flagelo-ministro-vallejo

21 Colombia, Decreto 100 de 1980, por la cual se expide el nuevo Código Penal, 35.461 Diario Oficial, 20 de febrero de 1980. Disponible en: http://www.suin-juriscol.gov.co/viewDocument.asp?id=1705120

22 Martha Isabel Gómez-Vélez, Aproximación al derecho penal ambiental: ideas para su abolición, 72 Estudios de Derecho, 160, 309-329, 315 (2015). Disponible en: https://aprendeenlinea.udea.edu. co/revistas/index.php/red/article/view/323345/20780548

23 La propuesta inicial era la de crear unas circunstancias de agravación a este delito. Cfr. Colombia, Proyecto de Ley 164 de 2010, Senado, por medio de la cual se reforma el Código Penal, el Código de Procedimiento Penal, el Código de Infancia y Adolescencia, las reglas sobre Extinción de Dominio y se dictan otras disposiciones en materia de seguridad, 737 Gaceta del Congreso, 5 de octubre de 2010. Disponible en: http://www.imprenta.gov.co/gacetap/gaceta.indice?v_num $=737 \& v \_a n o g=2010$ 
artículos habían sido pactados entre el Viceministerio de Justicia, la Fiscalía General y algunos miembros del Congreso ${ }^{24}$, por lo que al momento de someterlos a consideración tan solo se mencionaba el texto del delito reformado sin ahondar en la discusión sobre la necesidad, pertinencia o alcance de la reforma.

Lo paradójico es que casi todos los artículos relativos a la protección de los recursos naturales y el medio ambiente fueron reformados, excepto el 338 que era el que inicialmente había motivado la modificación, tal como se desprende del Proyecto 164 de 2010 de $\mathrm{Senado}^{25}$.

Estos constantes cambios en los delitos ambientales en Colombia generan una serie de dudas en cuanto a la verdadera necesidad de intervención, lo que incide en la eficacia y eficiencia del derecho penal para lograr su cometido, esto es, la protección de bienes jurídicos. Además, no puede perderse de vista que los ilícitos penales son a su vez ilícitos administrativos ambientales, bajo el entendido de que para la configuración del delito es necesario que se demuestre el desconocimiento de las normas administrativas sobre esta materia como elemento objetivo de la tipicidad. Ahora, no puede solo señalarse que ante la escasa intervención y eficacia del derecho administrativo deba el derecho penal entrar a brindar esa protección al bien jurídico, pues ello desfigura la función del derecho penal; en ese sentido, el bien jurídico penal debe ser merecedor de ese tratamiento por su importancia y por la gravedad de los ataques que ha de soportar, pero no puede avalarse la intervención penal por la inacción de las demás ramas del derecho.

Si bien es cierto que determinadas actividades se han considerado como mayormente atentatorias contra el medio ambiente, lo que avalaría la intervención del derecho penal, también lo es que el Estado debería hacer uso de su potestad sancionadora para fortalecer el control, vigilancia y protección del ambiente por la vía adminis-

24 Laura Rojas-Escobar, Análisis politico criminal y dogmático del delito de daños en los recursos naturales en Colombia (art. 331 CP) (Tesis de maestría en Derecho Penal, Universidad EAFIT, Medellín, 2014). Disponible en: https://repository.eafit.edu.co/handle/10784/2969\#.WYjytFHyiM8

25 Colombia, Proyecto de Ley 164 de 2010, Senado, por medio de la cual se reforma el Código Penal, el Código de Procedimiento Penal, el Código de Infancia y Adolescencia, las reglas sobre Extinción de Dominio y se dictan otras disposiciones en materia de seguridad, 737 Gaceta del Congreso, 5 de octubre de 2010 . 
trativa, al evitar que todas las conductas lleguen al conocimiento del derecho penal y salvaguardar así el principio de ultima ratio ${ }^{26}$.

Hecha la salvedad de que no cualquier conducta que afecte el medio ambiente debe ser perseguida penalmente, es necesario centrar la atención en aquellas que el legislador decidió que sí son merecedoras de tal protección, en especial por el impacto adverso que generan contra el bien jurídico tutelado.

En materia de protección al medio ambiente por el desarrollo de la actividad minera se han establecido dos conductas punibles, en primer lugar, el delito de contaminación ambiental por explotación de yacimiento minero o hidrocarburos del artículo $333 \mathrm{CP}$ $\mathrm{y}$, en segundo lugar, el delito de explotación ilícita de yacimiento minero y otros materiales, contenido en el artículo $338 \mathrm{CP}$. Este último castiga con pena de prisión la minería ilegal que, como se ha indicado antes, abarca el desarrollo de diversas clases de minería (informal, ilegal propiamente dicha y criminal). Esto permite concluir que por más que el ente acusador pretenda señalar que sus esfuerzos están centrados en investigar la minería criminal, ello no impide que también sean judicializados y condenados quienes actúen ilegalmente, aun cuando no pertenezcan a grupos armados al margen de la ley.

Ahora, como se ha indicado, pese a la existencia de estas dos conductas penales, este artículo se centrará en el delito del artículo $333 \mathrm{CP}$, principalmente porque fue el que mayores modificaciones sufrió tras la reforma de 2011 que, a juicio de la doctrina, hacen muy difícil su aplicación real ${ }^{27}$.

26 Cfr. Diego-Manuel Luzón-Peña, Lecciones de derecho penal, Parte general, 22-23 (3 $3^{\text {a }}$ ed., Tirant lo Blanch, Valencia, 2016). Agustín Jorge-BARreiro, El bien jurídico protegido en los delitos contra el medio ambiente en el CP de 1995, en Estudios sobre la protección penal del medio ambiente en el ordenamiento jurídico español, 1-72, 22 (Agustín Jorge-Barreiro, dir., Comares, Granada, 2004). Julio César Rodas-Monsalve, La protección penal del medio ambiente y la función simbólica del derecho penal, 5 Revista de Derecho Público, 149-154, 152 (1994).

27 Ver por todos: Blanca María González-Aldana \& Juan Alejandro Morales-Sierra, Normatividad penal y minería sin el cumplimiento de los requisitos legales, en Minería en Colombia: Daños ecológicos y socio-económicos y consideraciones sobre un modelo minero alternativo, 449-491, 459 (Contraloría General de la Nación, Bogotá, 2014). Disponible en: https://justiciaambientalcolombia. org/2014/08/11/mineria-colombia-danos-eco-socio-economicos-y-modelo-alternativo/ 


\section{BIEN JURÍdICO PROTEGIDO POR EL DELITO DE CONTAMINACIÓN AMBIENTAL POR EXPLOTACIÓN DE YACIMIENTO MINERO O HIDROCARBURO}

\section{A. La norma}

Artículo 333. Contaminación ambiental por explotación de yacimiento minero o hidrocarburo. El que provoque, contamine o realice directa o indirectamente en los recursos de agua, suelo, subsuelo o atmósfera, con ocasión a la extracción o excavación, exploración, construcción y montaje, explotación, beneficio, transformación, transporte de la actividad minera o de hidrocarburos, incurrirá en prisión de cinco (5) a diez (10) años, y multa de treinta mil (30.000) a cincuenta mil (50.000) salarios mínimos legales mensuales vigentes.

\section{B. Bien jurídico protegido}

Con los cambios introducidos por el nuevo CP colombiano en el año 2001 se despejan, aparentemente, las dudas relacionadas con la independencia del bien jurídico protegido, pues se plantea como uno de carácter autónomo ${ }^{28}$, por lo que ya no se requiere probar la afectación al bien jurídico socioeconómico para demostrar la lesividad material de una conducta ${ }^{29}$.

28 El CP de 1980 establecía los delitos contra los recursos naturales y el medio ambiente en el capítulo II, De los delitos contra los recursos naturales, bajo el Título VII, Delitos contra el Orden Económico Social.

29 Cierto sector de la doctrina considera que la independencia es meramente formal - mas no material一, al señalar la existencia de una relación económica entre la explotación de los recursos y el aspecto capitalista que hay detrás de él. En todo caso, aun cuando se comparte esta posición, la misma se hace con una visión eminentemente político criminal; empero, desde el plano dogmático, cuando se determina la afectación al bien jurídico, no es necesario entrar a determinar la lesión al aspecto socioeconómico, pues se ha de centrar en la lesión o puesta en peligro de los recursos naturales y el medio ambiente. Cfr. Martha Isabel Gómez-Vélez, Aproximación al derecho penal ambiental: ideas para su abolición, 72 Estudios de Derecho, 160, 309-329 (2015). 
El contenido del bien jurídico penal ambiental se mueve entre tesis antropocéntricas ${ }^{30} \mathrm{y}$ ecocéntricas ${ }^{31}$. Hay ordenamientos jurídicos que adoptan visiones hacia alguno de los dos supuestos y otros tienen una tendencia mixta ${ }^{32}$. Esta última posición es la adoptada por el Código Penal colombiano, lo cual se explica si se entiende que el punto de partida del establecimiento de un bien jurídico penal es la propia Constitución del Estado ${ }^{33}$. Así, la Constitución colombiana en diversos artículos hace referencia a la protección de los recursos naturales y del medio ambiente ${ }^{34}$, y no circunscribe esa protección a un asunto de interés exclusivo para la vida o la salud de las personas pues en ocasiones los protege en razón a sí mismos. Por esta razón, puede afirmarse que la visión que se adopta desde la Carta Fundamental en relación con la protección del medio ambiente es mixta, con una tendencia marcada al ecocentrismo, denominada ecoantropocentrismo ${ }^{35}$.

30 Una visión antropocéntrica establece que la tutela ambiental se relaciona directamente con la tutela del ser humano. El medio ambiente no puede ser protegido en sí mismo, sino que se protege porque es necesario para el equilibrio de la vida humana, de tal manera que cuando se afecte al ambiente, esta afectación a su vez debe poner en peligro o lesionar la vida o la salud humana, lo cual justifica la intervención del derecho penal. Cfr. Agustín Jorge-Barreiro, El bien jurídico protegido en los delitos contra el medio ambiente en el CP de 1995, en Estudios sobre la protección penal del medio ambiente en el ordenamiento jurídico español, 1-72, 40 (Agustín Jorge-BARReIro, dir., Comares, Granada, 2004). Legislaciones como las de Argentina o Panamá adoptan esta visión.

31 Para las concepciones ecocéntricas: el medio ambiente se protege en sí mismo, como un bien ideal, que no requiere conexión alguna con el ser humano, por ejemplo, el equilibrio de los ecosistemas sería el bien jurídico tutelado. Cfr. Agustín Jorge-Barreiro, El bien jurídico protegido en los delitos contra el medio ambiente en el CP de 1995, en Estudios sobre la protección penal del medio ambiente en el ordenamiento jurídico español, 1-72, 41 (Agustí Jorge-Barreiro, dir., Comares, Granada, 2004). Bolivia, Ecuador, México adoptan esta tendencia.

32 Las visiones mixtas pueden ser tanto antropocéntricas moderadas o ecocéntricas moderadas. Cfr. Agustín Jorge-Barreiro, El bien jurídico protegido en los delitos contra el medio ambiente en el CP de 1995, en Estudios sobre la protección penal del medio ambiente en el ordenamiento jurídico español, 1-72, 41-46 (Agustín Jorge-Barreiro, dir., Comares, Granada, 2004). A esta postura se adscriben países como Colombia, España, Brasil, Alemania.

33 Colombia, Constitución Política, versión corregida 116 Gaceta Constitucional, 20 de julio de 1991. Disponible en: http://www.secretariasenado.gov.co/senado/basedoc/constitucion_politica_1991. html

$34 \mathrm{Al}$ respecto, la Corte señala que esta Constitución ecológica: "está conformada por todas aquellas disposiciones que regulan la relación entre la sociedad y la naturaleza, y cuyo propósito esencial, es la protección del medio ambiente, la tutela al medio ambiente, que en un principio irradia el orden jurídico, de otro lado aparece el derecho de todas las personas a gozar de un ambiente sano, y finalmente, de la Carta se deriva un conjunto de obligaciones impuestas a las autoridades estatales y a los particulares". Colombia, Corte Constitucional, Sentencia C-495-96, 26 de septiembre de 1996, magistrado ponente Fabio Morón-Díaz. Disponible en: http://www.corteconstitucional.gov. co/relatoria/1996/C-495-96.htm

35 Yesid Ramírez-Bastidas, El delito ecológico, 301-304 (Ediciones Doctrina y Ley, Bogotá, 2007). 
Si bien las tendencias actuales están dirigidas a considerar al ecocentrismo como la tendencia más adecuada para proteger el medio ambiente, no puede descartarse de plano una visión antropocéntrica del mismo, de tal manera que debe entenderse que estas visiones pueden coexistir pues no son excluyentes sino complementarias ${ }^{36}$. Así las cosas, el ecocentrismo permite una protección más autónoma y liberada de aparentes conceptos utilitaristas, pero ello no quiere decir que el antropocentrismo sea equivocado y por tanto deba ser abandonado, pues estas tesis también vienen a controlar la existencia de un ecocentrismo excesivo ${ }^{37}$. En materia penal, la coexistencia de estas dos visiones es muy clara y se encuentran en el CP colombiano delitos que se fundamentan en una visión más que en otra, lo que reafirma que así como la Constitución adopta una visión mixta, el derecho penal también lo hace, aunque es muy claro que hay una mayor inclinación hacia el ecocentrismo ${ }^{38}$. Ello viene a explicar por qué no todos los delitos están referidos en cuanto a su lesividad a la afectación de algún bien jurídico individual como la integridad o la vida y, en cambio, sí se protegen por ejemplo conductas que pretenden salvaguardar el medio ambiente en sí mismo considerado, como el delito de daño en los recursos naturales.

36 Así se pronuncia José Manuel Paredes-Castañón, Derecho penal español del medioambiente: una evaluación crítica, en Libro homenaje al profesor Luis Rodríguez Ramos, 751-770 (Francisco JAVIER Álvarez-García, Miguel Ángel Cobos-Gómez de Linares, Pilar Gómez Pavón, Araceli ManjónCabeza Olmeda \& Amparo Martínez-Guerra, Tirant lo Blanch, Valencia, 2013), al indicar que teniendo en cuenta los ataques a los que se ve sometido el medio ambiente, cada vez se abandona una visión eminentemente antropocéntrica del ambiente, para dar paso a tendencias mixtas o bien meramente ecocéntricas que les otorgan relevancia y valor a los elementos compositivos del ecosistema por su importancia en el equilibrio ecológico. Resulta claro que las alteraciones al ecosistema pueden desencadenar efectos de diversas proporciones; por ello, resulta pertinente adoptar visiones que pretendan proteger el ambiente por su valor.

37 Vale la pena señalar que una de las corrientes que se desprenden del ecocentrismo es el biocentrismo; este enfoque es principalmente de contenido ético, que considera que el ser humano y el ambiente están en las mismas condiciones. Por ello, esta visión les otorga el mismo valor al hombre y a la naturaleza (principalmente se refiere a los seres vivos). De acuerdo con esta teoría, el hombre es un ser vivo más de los que se encuentran en la naturaleza; por ello, no hay razón alguna para considerarlo como un ser superior. Se rompe entonces con la consideración jerárquica que planteaba la tesis antropocéntrica. En esta corriente se entiende que "todas las cosas vivientes se ven ahora como los objetos a los que se dirige la actitud de respeto y que consideran, en consecuencia, como entidades que poseen valor inherente". PAUL W. TAYLOR, La ética del respeto a la naturaleza, en Los caminos de la ética ambiental. Una antología de textos contemporáneos, 269-288, 272 (TERESA Kwiatkowska \& Jorge Issa, comps., Plazas y Valdés Editores, México, 1998).

38 Yesid Ramírez-Bastidas, El delito ecológico, 301-304 (Ediciones Doctrina y Ley, Bogotá, 2007). 
Así entonces, en Colombia se pretende proteger el ambiente por dos grandes razones: 1. La importancia del ambiente para el ser humano. 2. Por la importancia de los recursos naturales para el Estado colombiano en general.

\section{iI. PROBlemas en torno al Delito}

Basta con hacer una lectura primaria del delito del artículo 333 para advertir su confusa redacción. Normalmente, estos problemas se achacan a una indebida técnica legislativa, por lo que bastaría con determinar lo que pretendió el legislador para superar la "confusión"; empero, la tipificación del delito de contaminación ambiental por explotación de yacimiento minero posee graves deficiencias que llevarán a concluir que ese tipo penal es inconstitucional.

De otro lado, en caso de aceptarse la superación de los inconvenientes legislativos mencionados, se realizará un abordaje dogmático del delito para identificar los principales elementos y los problemas que de él se derivan.

Antes de analizar el delito actual, es preciso hacer mención a la redacción de la norma anterior, ya que ello nos dará ciertas pautas para establecer las dificultades en torno al delito vigente. Antes de la Ley 1453 de 2011, el artículo 333 establecía: "El que por culpa al explorar, explotar o extraer yacimiento minero o de hidrocarburos, contamine aguas, suelo, subsuelo o atmósfera, incurrirá en prisión de dos (2) a cinco (5) años, y multa de cien (100) a cincuenta mil (50.000) salarios mínimos legales mensuales vigentes".

La norma actual elimina la referencia culposa del delito y lo convierte en doloso, aunque con la remisión del artículo 339 CP también cabe la modalidad culposa. Igualmente, establece dos nuevos verbos rectores que se suman al de contaminar que son provocar o realizar, que se pueden cometer de manera directa o indirecta.

\section{A. Los verbos rectores y la posibilidad de comisión real del delito}

Provocar, de acuerdo con el DRAE significa producir o causar algo ${ }^{39}$; por su parte realizar es efectuar, llevar a cabo algo o ejecutar una

39 Diccionario de la Real Academia Española: http://dle.rae.es/?id=UUqWrZ7 
acción ${ }^{40}$; mientras que contaminar hace referencia a alterar nocivamente la pureza o las condiciones normales de una cosa o un medio por agentes químicos ofísicos ${ }^{41}$.

El problema no recae en la inclusión de estos dos nuevos verbos rectores, sino en que de la redacción del delito no resulta claro cuándo al realizarlos se comete un ilícito penal, a excepción del verbo contaminar, aun cuando esta última posibilidad se asume desde una perspectiva muy discutida.

Surgen entonces algunos interrogantes. ¿Resulta punible la mera realización de una extracción de suelo en el desarrollo de la actividad de explotación de yacimiento minero? ¿Resulta punible la sola construcción o montaje para la excavación de un yacimiento minero? ¿Cuándo realizar transporte de la actividad minera resulta punible y cuando no lo es? No parece lógico que el ejercicio de actividades necesarias para la explotación de yacimiento minero sea sancionado penalmente sin que se indique la lesividad al bien jurídico protegido. Ahora, si bien toda actividad minera genera un efecto negativo en los recursos que son considerados objetos materiales del delito, esto es, el agua, el suelo, subsuelo o atmosfera, el Estado ha decidido avalar el ejercicio de la minería, por lo que puede suponerse que el legislador no pretendía sancionar penalmente el mero desarrollo de la misma, aunque finalmente ese fue el resultado.

Esta situación plantea la inconstitucionalidad de la norma pues el supuesto de hecho delictivo no está totalmente delimitado, lo cual le impide al ciudadano conocer lo que está permitido o prohibido por la norma penal.

En materia de derecho penal, el principio de legalidad adquiere una importancia innegable ${ }^{42}$, de tal forma que le corresponde al legislador establecer de manera previa, cierta, escrita y estricta el contenido de cada delito y de cada pena ${ }^{43}$. La estructura de

40 Diccionario de la Real Academia Española: http://dle.rae.es/?id=VHUV2Pi

41 Diccionario de la Real Academia Española: http://dle.rae.es/?id=AU1m1dd

42 Al respecto: Eugenio Zaffaroni, Manual de derecho penal, Parte general, 106 (Ediar/Temis, Buenos Aires, 2005). Fernando Velásquez-Velásquez, Manual de derecho penal, Parte general, 76 (4a ed., Ediciones Jurídicas Andrés Morales, Bogotá, 2010). Fernando Velásquez-Velásquez, Derecho penal, Parte general, 131 (4 ed., Comlibros, Bogotá, 2010).

43 Al respecto, Claus Roxin indica que hay cuatro consecuencias del principio de legalidad: 1. La prohibición de analogía (nullum crimen, nulla pœena sine lege); 2 . La prohibición de derecho consuetudinario para fundamentar y para agravar la pena (nullum crimen, nulla pœna sine lege scripta); 3. La prohibición de retroactividad (nullum crimen, nulla pæena sine lege prcevia); y 4. La prohibición de leyes penales y penas indeterminadas (nullum crimen, nulla pæna sine lege certa). Cfr. Claus 
cualquier norma debe contener un supuesto de hecho y una consecuencia, redactados con toda la claridad posible, de tal manera que no haya dudas de que si A entonces B. Además, debe indicarse que las normas penales contienen dos preceptos identificados como norma primaria y otra secundaria. La primera está dirigida a los ciudadanos por cuanto en ella se establece lo que está prohibido; y, por otro lado, la norma secundaria está dirigida al juez, pues es la que le indica cuál es la pena que se debe imponer por la comisión de un delito ${ }^{44}$.

Esta norma primaria está absolutamente indeterminada en este delito, pues no diferencia la acción delictiva de la no delictiva, en cuanto a que la realización de los verbos rectores (realizar, provocar, y si se quiere entraría también contaminar) son actividades comunes y normales de la actividad minera. Acá se ha mencionado cómo el desarrollo de la minería genera efectos adversos contra los recursos naturales; ahora, lo que pretende el Estado al regular la actividad minera es mitigar los efectos negativos contra el medio ambiente; pero no hacerlos desaparecer, porque ello es imposible. Entonces, cuando el legislador dice que es delito "provocar o realizar excavaciones, extracciones, exploraciones, construcciones, montajes, explotación, beneficio, transformación o transporte que recaiga sobre los recursos de agua, suelo, subsuelo, o atmósfera en el ejercicio de la actividad minera o hidrocarburos", no está haciendo otra cosa que describir el desarrollo de esta actividad, por lo cual no es claro entonces el supuesto prohibido por la norma.

El artículo 10 del Código Penal al referirse a las normas rectoras de la ley penal colombiana, establece el principio de tipicidad en los siguientes términos: "La Ley penal definirá de manera inequívoca, expresa y clara las características básicas estructurales del tipo penal. En los tipos de omisión también el deber tendrá que estar consagrado y delimitado claramente en la Constitución Política o en la Ley", este principio es el desarrollo de una de las garantías que se consagran en el artículo 29 de la Constitución Política de Colombia, pues "nadie podrá ser juzgado sino conforme a leyes preexistentes

Roxin, Derecho penal, Parte general, II, 140-142 (Madrid, Civitas, 1997).

44 Diego-Manuel Luzón-Peña, Lecciones de derecho penal, Parte general, 58 ( $3^{\mathrm{a}}$ ed., Tirant lo Blanch, Valencia, 2016). 
al acto que se le imputa, ante juez o tribunal competente y con observancia de la plenitud de las formas propias de cada juicio".

Además, la Corte Constitucional, en reiterada jurisprudencia, ha señalado que la inobservancia de los requisitos del principio de legalidad penal viene a sustentar la inconstitucionalidad de la norma ${ }^{45}$. Así:

En materia penal, el principio de legalidad vincula no solo a los jueces sino también al propio legislador pues ese principio constitucional consagra un doble mandato: así, ordena a los jueces que solo sancionen conductas previamente establecidas en la ley, pero a su vez, impone al Legislador el deber de definir de tal manera las conductas punibles, que estas sean inequívocas y empíricamente verificables. Solo así los jueces estarán verdaderamente sometidos a la ley y se asegura el derecho de defensa de los acusados, quienes tienen entonces la posibilidad de refutar en el proceso las acusaciones precisas que les formula el Estado. En tales circunstancias, la Corte concluye que la mala redacción de una norma que define un hecho punible no es un asunto de poca monta sino que tiene relevancia constitucional, puesto que puede afectar el principio de legalidad penal estricta, ya que no queda clara cuál es la conducta que debe ser sancionada ${ }^{46}$ (negrillas fuera del texto).

Todo lo expuesto lleva a fundamentar que el delito en cuestión es inconstitucional. Empero, ante la falta de declaratoria de inconstitucionalidad de esta norma, debe el juez evitar aplicarla por la afectación a los derechos que se han señalado a lo largo de este artículo $^{47}$.

De otro lado, como se planteó anteriormente, aunque las principales críticas a este artículo gravitan en torno a los verbos rectores

45 Colombia, Corte Constitucional, Sentencia C-133-99, 3 de marzo de 1999, magistrado ponente Carlos Gaviria-Díaz. Disponible en: http://www.corteconstitucional.gov.co/relatoria/1999/C-133-99.htm. Colombia, Corte Constitucional, Sentencia C-238-05, 15 de marzo de 2005, magistrado ponente Jaime Araujo-Rentería. Disponible en: http://www.corteconstitucional.gov.co/relatoria/2005/c-238-05. htm. Colombia, Corte Constitucional, Sentencia C-191-16, 20 de abril de 2016, magistrado ponente Alejandro Linares-Cantillo. http://www.corteconstitucional.gov.co/relatoria/2016/c-191-16.htm

46 Colombia, Corte Constitucional, Sentencia C-559-99, 4 de agosto de 1999, magistrado ponente Alejandro Martínez-Caballero. Disponible en: http://www.corteconstitucional.gov.co/ relatoria/1999/c-559-99.htm

47 Debe recordarse que en Colombia opera el control de constitucionalidad difuso, por medio del cual los jueces de la República pueden ampararse en la excepción de inconstitucionalidad que ha sido definida como la herramienta que "se usa con el fin de proteger, en un caso concreto y con efecto inter partes, los derechos fundamentales que se vean en riesgo por la aplicación de una norma de inferior jerarquía y que, de forma clara y evidente, contraría las normas contenidas dentro de la Constitución Política". Cfr. Colombia, Corte Constitucional, Sentencia SU132-13, 13 de marzo de 2013, magistrado ponente Alexei Julio-Estrada. Disponible en: http://www.corteconstitucional.gov. co/relatoria/2013/su132-13.htm 
"provocar y realizar", y pese a que podría cobijar también el de "contaminar", lo cierto es que la Fiscalía General de la Nación realiza imputaciones conforme a esta norma al aplicar aparentemente este verbo rector, con lo cual hace una interpretación sistemática del Código y se remite a la normatividad reguladora en la materia, es decir, al Código de Minas, que establece que para ejercer la actividad minera se deben tomar ciertas precauciones y cuando ello no se hace, surge este delito. Es decir, se aplica, al igual que con los otros delitos de contaminación ambiental, un criterio de niveles de contaminación permitidos, de tal manera que si este se sobrepasa se estará en presencia del acto delictivo.

Así las cosas, si solo se leyera el delito, aun con el verbo rector "contaminar" habría dificultades en torno a su aplicación; sin embargo, teniendo en cuenta la tesis de la Fiscalía, la tipicidad de la conducta se determinará cuando esa contaminación supere el riesgo permitido establecido en las normas existentes aplicables a ese caso.

Ante esta solución, podrían plantearse dos escenarios. El primero en el que quien realiza la actividad minera cuenta con los permisos, licencias y autorizaciones para ejercer esta labor, pero en ejercicio de su oficio "contamina directa o indirectamente los recursos de agua, suelo, subsuelo o atmósfera, con ocasión a la extracción o excavación, exploración, construcción y montaje, explotación, beneficio, transformación, transporte de la actividad minera o de hidrocarburo", es decir, realiza objetiva y subjetivamente la acción descrita en el artículo 333, por tanto, el examen de tipicidad estaría completo y se debe acudir a la antijuridicidad para determinar la efectiva lesión o puesta en peligro del bien jurídico tutelado. Como puede pensarse, una solución así sería bastante compleja y sobre todo inoficiosa toda vez que la determinación de la ausencia de antijuridicidad debe valorarse judicialmente. En estos casos, la mejor solución sería la de plantear una ausencia de tipicidad tal como lo señala Diego-Manuel Luzón-Peña pues ello supone "la exclusión material del tipo indiciario y por tanto la ausencia de entrada de cualquier relevancia delictiva (e incluso jurídica) de la conducta, una vez constatada su presencia lógicamente deben suponer la no iniciación del procedimiento penal"48. La solución que se plantea

48 Diego-Manuel Luzón-Peña, Lecciones de derecho penal, Parte general, 325 (3ª ed., Tirant lo Blanch, Valencia, 2016). 
entonces es la de considerar esta acción como atípica en este supuesto por contar con autorización oficial para funcionar y además, porque no habría superación del riesgo permitido ${ }^{49}$.

El segundo escenario planteado sería el de una persona que sin contar con título minero y mucho menos con licencias ambientales ejerce la actividad minera, es decir, su actuar se encuadra en una actividad de minería ilegal, pero, además, en su desarrollo, realiza actos de contaminación ambiental. Acá no podría hablarse de atipicidad por autorización oficial para funcionar, pues la misma no existe, por lo que debería determinarse si el acto de contaminación supera los riesgos permitidos en el desarrollo de explotación minera. Aunque puede haber atipicidad de la conducta en caso de que ello sea así, esto no lo exime de la comisión del delito de explotación ilícita de yacimiento minero y otros minerales (artículo $338 \mathrm{CP}$ ). O bien, si se superan los riesgos permitidos podría llegar a haber un concurso de delitos entre el 333 y el 338 del Código Penal.

\section{B. ¿Y las normas penales en blanco?}

Una de las principales características de los delitos ambientales es que hacen uso de las normas o leyes penales en blanco pues remiten parte del supuesto de hecho a otra norma extrapenal ${ }^{50}$. Así, el Código Penal colombiano usa la fórmula del "incumplimiento de la normatividad existente" para remitir a las normas administrativas que regulan las diversas actividades que tienen incidencia con el medio ambiente.

El problema señalado en el aparte anterior en cuanto a que no es clara la lesividad de la conducta tiene mucha relación con la falta de una remisión a la normatividad que regula la actividad minera

49 Ha de tenerse en cuenta que se plantea la aplicación de causales que excluyen la tipicidad por ausencia de antijuridicidad. Como se puede advertir, estas causales tienen especial importancia en la teoría de los elementos negativos del tipo, en la que se establecen ciertas casuales de atipicidad en un sentido amplio y se abarcan también causas de justificación. Así, entonces, ciertos casos de autorización oficial estarían amparados por una casual de atipicidad cuando dicha autorización es válida por falta de toda relevancia jurídica o "porque no hay lesión o afectación del bien jurídico supraindividual o colectivo, y dado que ya es presupuesto del tipo y de cualquier ilicitud una actuación contra la voluntad de la autoridad, o porque la afectación del bien jurídico no es jurídicamente relevante por adecuación social". Diego-Manuel Luzón-Peña, Lecciones de derecho penal, Parte general, 324 ( $3^{\mathrm{a}}$ ed., Tirant lo Blanch, Valencia, 2016).

50 Cfr. Diego-Manuel Luzón-Peña, Lecciones de derecho penal, Parte general, 59 (3 ${ }^{\mathrm{a}}$ ed., Tirant lo Blanch, Valencia, 2016). 
pues ello generaría seguridad en cuanto a los límites, requisitos o procedimientos que habría que cumplir.

$\mathrm{Si}$, como parece, el delito de contaminación ambiental por explotación de yacimiento minero es una clase de contaminación ambiental como también lo es la contaminación ambiental por residuos sólidos peligrosos (artículo 332A), no se entiende cómo en relación con estas otras conductas sí se hace uso de las normas penales en blanco; pero en este caso, no. La explicación no puede ser otra que la siguiente: el legislador - al momento de modificar el artículo - no analizó detenidamente su redacción. Recuérdese que la norma anterior tampoco hacía remisión a normas penales en blanco, pero porque el delito era de carácter culposo, es decir, se incurría en el mismo cuando obrara inobservancia al deber objetivo de cuidado, que para el caso concreto serían las normas administrativas que regulan la actividad minera y por ello no era necesario hacer esta remisión. Empero con la actual norma sí se considera importante pues ello vendría a determinar los límites y riesgos permitidos en el ejercicio de la actividad minera.

\section{C. ¿Delito de peligro abstracto o de lesión?}

De acuerdo con lo que se ha venido sosteniendo en este trabajo, de los tres verbos rectores que contiene la norma del artículo $333 \mathrm{CP}$, el único que podría llegar a tener una aplicación real sería el de "contaminar"; claro está, bajo el entendido de que ha de hacerse una interpretación sistemática del delito, debido a las deficiencias de redacción que la norma presenta. Ahora, no hay en Colombia una jurisprudencia consolidada en materia de delitos ambientales, a excepción de algunos pronunciamientos en torno al delito de contaminación del artículo 332 y el delito de daño en los recursos naturales del artículo 331. En relación con el delito que nos ocupa, no hay una sola sentencia que haga referencia al mismo, lo que podría llegar a ser bastante útil para aclarar los inconvenientes que se han puesto de presente en este documento. Ante este vacío, la Fiscalía toma la jurisprudencia que sobre el delito de contaminación ambiental se ha emitido y la aplica a este delito en particular. Es decir, la interpretación de la Fiscalía es que al ser el mismo verbo 
rector, lo dicho en relación con la conducta se aplica a este ilícito mutatis mutandis.

La Corte Suprema de Justicia en sentencia del 19 de febrero de 2007 sentó una postura en torno a la interpretación del delito de contaminación ambiental ${ }^{51}$. Los hechos del caso son los siguientes: El señor Salamanca arrendó un predio rural al señor Umbarila, por distintos motivos el arrendador pretendió recuperar el bien y cuando ingresó al mismo encontró envases y recipientes de insumos químicos esparcidos sobre todo el terreno, lo que abarcaba los pozos de agua; señaló además que ello había causado la muerte de un semoviente pues este ingirió parte de los residuos tóxicos. El debate giró en torno a varios aspectos, siendo el principal el relacionado con la muerte del referido animal, pues no había suficientes elementos probatorios que determinaran que el deceso había sido producto de la ingesta de los compuestos químicos dispuestos en el terreno.

En primera instancia, el señor Umbarila fue absuelto; la parte civil interpuso recurso de apelación y el Tribunal confirmó la sentencia absolutoria. Ante ello, se instauró demanda de casación penal. El cargo que interesa para este estudio fue redactado así:

La sentencia viola de manera directa la ley sustancial por falta de aplicación del artículo 247 del Código Penal de 198052, que define el delito de contaminación ambiental, debido a un error de carácter jurídico, originado en una interpretación equivocada de los contenidos normativos del precepto.

El Tribunal, al afirmar en la sentencia que la contaminación ambiental no se encontraba acreditada porque "el perito no determinó que la muerte de la vaca haya obedecido, con absoluta seguridad, a la ingestión del mismo, sino únicamente, que pudo ser originada por este compuesto", le dio al contenido de la norma unos alcances que no le corresponden, y condicionó la estructu-

51 Colombia, Corte Suprema de Justicia, Sala de Casación Penal, Proceso 23286, 19 de febrero de 2007, magistrado ponente Mauro Solarte-Portilla. Esta postura ha sido reiterada sin reparos en relación con la interpretación que se hace del verbo rector contaminar y de la lesión al bien jurídico. Así ha sido señalado en: Colombia, Corte Suprema de Justicia, Sala de Casación Penal, Proceso 27035, 15 de mayo de 2008, magistrado ponente Javier Zapata-Ortiz. Colombia, Corte Suprema de Justicia, Sala de Casación Penal, Proceso 47504, 1 de junio de 2016, magistrado ponente Gustavo Enrique Malo-Fernández.

52 Se aclara que los hechos ocurrieron en vigencia del CP de 1980 que establecía en el artículo 247 el delito de contaminación ambiental. Estas sentencias en general asimilan la redacción de esta norma a la actual (artículo 332) al considerar que el verbo rector contaminar ha permanecido inalterable, pese a las diferentes modificaciones. 
ración del delito a la muerte de los seres que padecen las consecuencias de la contaminación.

La determinación de la causa de la muerte resulta indiferente para el proceso de adecuación de la conducta típica, por no formar parte de los elementos del tipo penal, y porque una correcta intelección del precepto, armonizada con lo previsto en el Código Nacional de Recursos Naturales Renovables ${ }^{53}$, "permite concluir que la contaminación se presenta sin necesidad de que la interferencia al bienestar y la salud de las personas, las plantas y los animales, impliquen su total destrucción o aniquilamiento" ${ }^{54}$.

Al respecto, tanto la Fiscalía como el Ministerio Público coincidieron en señalar que hubo una indebida interpretación del delito, pues uno de los principales argumentos para fundamentar la absolución había sido que no había claridad en relación con la causa de la muerte del semoviente, lo cual no permitía afirmar que en efecto se había dado la consumación de la conducta (contaminar); al respecto, tanto la demandante como el Ministerio Público consideran que exigir la muerte del animal era un aspecto indiferente para el proceso de adecuación de la conducta típica, pues la norma no exige que la contaminación cause la muerte, por lo cual en últimas el Tribunal está exigiendo un requisito que no hace parte del tipo objetivo.

En ese sentido, para el demandante y para el Ministerio Público el delito existió en el mismo momento en el que fueron hallados los desechos tóxicos y químicos sin que fuera necesario advertir algún resultado adicional.

La Corte al entrar a referirse a cada uno de estos cargos se centra principalmente en el verbo rector del delito, señala entonces que el delito requiere que haya contaminación ambiental por tratarse de un delito de resultado, elemento que no fue acreditado en el proceso y advierte:

Contaminar, según el diccionario de la lengua española, significa, en su primera acepción, "alterar la pureza de alguna cosa, como los alimentos, el agua o el aire", entendimiento en el que ha de entendérsele, no solo por corresponder a

53 Colombia, Decreto Ley 2811 de 1974, por el cual se dicta el Código Nacional de Recursos Naturales Renovables y de Protección al Medio Ambiente, 34.243 Diario Oficial, 18 de diciembre de 1974. Disponible en: http://www.alcaldiabogota.gov.co/sisjur/normas/Norma1.jsp?i=1551

54 Colombia, Corte Suprema de Justicia, Sala de Casación Penal, Proceso 23286, 19 de febrero de 2007, magistrado ponente Mauro Solarte-Portilla. 
su sentido natural, sino porque en el mismo alcance es utilizado por el Código Nacional de Recursos Naturales Renovables, estatuto en el que se define la contaminación ambiental como "la alteración del ambiente con sustancias o formas de energía puestas en él, por actividad humana o de la naturaleza, en cantidades, concentraciones o niveles capaces de interferir el bienestar y la salud de las personas, atentar contra la flora y la fauna, degradar la calidad del ambiente de los recursos de la nación o de los particulares" 55 .

De acuerdo a lo anterior, la Corte considera que se trata en verdad de un delito de resultado en el entendido de que exige una transformación del mundo exterior (alteración del medio ambiente), y no un delito de mera conducta. Y en atención al bien jurídico, la Corte hace una diferenciación porque desprende del mismo delito dos efectos sobre el bien jurídico tutelado, uno primario, que se trata de un delito de lesión, pues exige la afectación del interés jurídico protegido, esto es los recursos naturales y el medio ambiente; $y$, en relación con los efectos secundarios, considera que la contaminación debe poner en peligro la salud humana, los recursos fáunicos, forestales, florísticos o hidrobiológicos.

La Corte además establece los requisitos que deben cumplirse:

1. Que se presente alteración al medio ambiente.

2. Que la contaminación generada por la conducta del sujeto agente desconozca los límites legalmente permitidos o racionalmente tolerados.

3. Que la contaminación causada tenga aptitud para causar daño o poner en peligro la salud humana o los recursos fáunicos, forestales, florísticos e hidrobiológicos ${ }^{56}$.

Esta posición de la Corte no deja de causar polémica, principalmente porque establece una interpretación contraria a lo señalado por la doctrina mayoritaria nacional e internacional, que han considerado el delito de contaminación ambiental como el prototipo de delito de peligro abstracto ${ }^{57}$. No se discute que la Corte considere

55 Colombia, Corte Suprema de Justicia, Sala de Casación Penal, Proceso 23286, 19 de febrero de 2007, magistrado ponente Mauro Solarte-Portilla.

56 Colombia, Corte Suprema de Justicia, Sala de Casación Penal, Proceso 23286, 19 de febrero de 2007, magistrado ponente Mauro Solarte-Portilla.

57 Por Colombia: José DANiel BARRERo-CÁCERES, La contaminación ambiental como delito de resultado, 1 Estudios en Derecho y Gobierno, 79-96 (2008). JuAn Galeano-Rey \& Julio MonTañEz-Ruiz, Delitos contra el medio ambiente y los recursos naturales, en Manual de Derecho penal, Parte Especial, II, 475-507, 491 (CArlos Guillermo Castro-Cuenca, coord., Temis, Bogotá, 2011). Por España: José 
que el verbo rector es de resultado; sin embargo, el que se afirme que en cuanto al bien jurídico ha de determinarse una lesión efectiva escapa del propósito mismo de protección de la norma.

Al parecer se incurre en un error al considerar que todo delito de resultado ha de ser de lesión, empero ha de señalarse que ciertos delitos de peligro abstracto pueden ser de resultado, así señala LuzónPeña: "los tipos de peligro abstracto generalmente son delitos de mera conducta, pero en algún caso pueden ser tipos de resultado" 58 .

De otro lado, es pertinente señalar que si bien el delito por el cual se acusaba al señor Umbarila era denominado como contaminación ambiental, su redacción es harto distinta.

El Decreto Ley 100 de 1980 señalaba: "Artículo 247. Contaminación ambiental. El que ilícitamente contamine el ambiente, incurrirá, sin perjuicio de las sanciones administrativas a que hubiere lugar y siempre que el hecho no constituya otro delito, en prisión de uno (1) a seis (6) años y multa de cincuenta mil a dos millones de pesos". Obsérvese cómo se trata de un delito de redacción simple en el cual tan solo era necesario determinar la existencia ilícita de una contaminación al ambiente en general. La simpleza del delito generaba grandes dificultades a la hora de establecer el ilícito penal.

Manuel Paredes-Castañón, Derecho penal español del medioambiente: una evaluación crítica, en Libro homenaje al profesor Luis Rodríguez Ramos, 751-770, 765 (Francisco JAVIER ÁlvarEZ-GARCía, Miguel Ángel Cobos-Gómez de Linares, Pilar Gómez Pavón, Araceli Manjón-Cabeza Olmeda \& Amparo Martínez-Guerra, Tirant lo Blanch, Valencia, 2013). Agustín Jorge-Barreiro, El bien jurídico protegido en los delitos contra el medio ambiente en el CP de 1995, en Estudios sobre la protección penal del medio ambiente en el ordenamiento jurídico español, 1-72, 28 (Agustín Jorge-Barreiro, dir., Comares, Granada, 2004). Mercedes Alonso-Álamo, La aporía del Derecho penal del medio ambiente, en Estudios de Derecho ambiental. Libro homenaje al profesor Josep Miquel Prats-Canut, 21-40 (Gonzalo Quintero-Olivares \& Fermín Morales-Prats, coords., Tirant lo Blanch, Valencia, 2008). Francisco Muñoz-Conde, María Carmen López-Peregrín \& Pastora García-Álvarez, Manual de derecho penal medioambiental, 249 (2a ed., Tirant lo Blanch, 2015). Klaus Tiedemann, Derecho penal y nuevas formas de criminalidad (Grijley, Lima, 2007). RolAnd HEFENDEHL, ¿Debe ocuparse el derecho penal de riesgos futuros? Bienes jurídicos colectivos y delitos de peligro abstracto, 4 Revista Electrónica de Ciencia Penal y Criminología, 14, 1-13 (2008). Disponible en: http://criminet.ugr.es/recpc/recpc_04-14.pdf. Nuria MatelLANES-RodríguEZ, Derecho penal del medio ambiente (Iustel, Madrid, 2008). Hernán HormazÁBal-Malarée, El principio de lesividad y el delito ecológico, en El nuevo derecho penal español. Estudios penales en memoria del profesor José Manuel Valle-Muñiz, 1417-1428 (Gonzalo Quintero-Olivares \& Fermín MoraLes-Prats, coords., Aranzadi, Navarra, 2001). CARlos Martínez-Buján, Lección XXXII, Delitos relativos a la ordenación del territorio y el urbanismo, la protección del patrimonio histórico y del medio ambiente, en Derecho penal, Parte Especial, 545-566, 545-560 (José Luis GonzÁlez-Cussac, coord., Tirant lo Blanch, Valencia, 2016). CARLos MARTínEZ-BujÁn, Derecho penal económico y de la empresa, Parte especial ( $5^{\mathrm{a}}$ ed., Tirant lo Blanch, Valencia, 2015).

58 Diego-Manuel Luzón-Peña, Lecciones de derecho penal, Parte general, 161 ( $3^{\mathrm{a}}$ ed., Tirant lo Blanch, Valencia, 2016). 
Si al momento en que se cometieron los hechos esta era la norma vigente, y como indica la Corte establecía "contaminar" como verbo rector, era válido interpretar la norma de la forma como en efecto se hizo. Sin embargo, no se puede estar de acuerdo con el hecho de que con las posteriores reformas y con la redacción actual se siga sosteniendo la misma tesis. No se discute que el verbo rector sea de resultado, pero no puede afirmarse que sea un delito de lesión, menos cuando el mismo delito establece "en tal forma que ponga en peligro la salud humana o los recursos fáunicos, forestales, florísticos o hidrobiológicos". Además, no se puede perder de vista la perspectiva desde la cual se protege el bien jurídico medioambiental, en el entendido de que no solo se pretenda salvaguardar la vida y la salud de las personas, sino también la existencia de los recursos naturales por sí mismos; en ese sentido, una interpretación tan restrictiva como la de la Corte desconoce el contenido del bien jurídico y su real protección.

Pero aplicando esa interpretación al delito de contaminación ambiental por explotación de yacimientos mineros e hidrocarburos, como lo hace la Fiscalía, es necesario entonces demostrar que se ha contaminado y lesionado efectivamente el bien jurídico tutelado, lo cual hace que su aplicabilidad sea muy limitada y — sobre todoque la intervención penal para la protección del bien jurídico sea tardía pues solo cuando hay una efectiva lesión habrá antijuridicidad, aun cuando el delito exija el solo peligro. 


\section{CONCLUSIONES}

1. El delito de contaminación ambiental por explotación de yacimiento minero e hidrocarburo es un claro ejemplo del ejercicio inadecuado de la labor de los legisladores en Colombia, quienes modifican o crean normas sin contar al menos con los requisitos mínimos para garantizar su existencia. Este delito es inconstitucional, tal como se ha señalado a lo largo de este trabajo; empero, hasta no contar con una sentencia que así lo declare el mismo continúa vigente, $\mathrm{y}$, lo que es peor, aplicándose.

2. Entender el delito de contaminación ambiental por explotación de yacimiento minero e hidrocarburos como un delito de resultado puede ser contrario a la aparente necesidad de la norma. Es decir, toda actividad minera genera efectos devastadores contra el medio ambiente, que se califican incluso de graves e irreversibles; entonces, no resulta claro por qué no se sanciona la mera puesta en peligro del bien jurídico, sino que deba esperarse a la lesión efectiva del mismo.

3. Político-criminalmente es más conveniente entender este delito como un típico delito de peligro, no como uno de lesión, por la misma necesidad de protección del bien jurídico, para adelantar las barreras punitivas con el fin de sancionar la actividad minera capaz de generar contaminación ambiental, sin exigir resultado alguno.

4. Si el legislador pretendía brindar una protección más específica a los recursos naturales cuando se realizaba la actividad de explotación minera, la redacción de la norma es del todo desafortunada, pues establece tres verbos rectores alternativos (provocar, contaminar o realizar), que se refieren a diversos objetos materiales (agua, suelo, subsuelo o atmósfera) y que se cometen con ocasión a la extracción o excavación, exploración, construcción, explotación, beneficio, transformación, transporte de la actividad minera o de hidrocarburos.

Es decir, el delito se comete cuando - en el ejercicio de la explotación de yacimiento minero - se contaminan suelo, subsuelo, agua o atmósfera. Pero los verbos rectores "provocar" y realizar" no tienen posibilidad clara de aplicación pues no se puede entender cuál es 
el supuesto delictivo que establece la norma. En otras palabras, el único verbo rector aplicable es el de contaminar, que es el mismo que está en el artículo 332 que establece la contaminación ambiental. Si se quería ser más explícito en relación con la actividad minera, y crear una mayor protección o límites a esta actividad, se debió establecer una circunstancia de agravación, por ejemplo, cuando la contaminación se realiza por explotación de yacimiento minero o hidrocarburo, pero dejando los mismos elementos del delito. 


\section{BIBLIOGRAFÍA}

\section{Libros}

Centro de Investigación y Educación Popular, CINEP, Programa por la Paz, Minería, conflictos sociales y violación de derechos humanos en Colombia, Segundo Informe especial (Centro de Investigación y Educación Popular, CINEP, Bogotá, 2012). Disponible en: http://www.alainet.org/images/IE_CINEP_octubre_2012.pdf

Garay-Salamanca, Luis Jorge (dir.); Cabrera-Leal, Mauricio; Espitia-Zamora, Jorge Enrique; Fierro-Morales, Julio; Negrete-Montes, Rodrigo E.; Pardo-Becerra, Luis Álvaro; Rudas-Lleras, Guillermo \& Vargas-Valencia, Fernando, Minería en Colombia: derechos, politicas públicas y gobernanza (Contraloría General de la República, Bogotá, 2013). Disponible en: https://redjusticiaambientalcolombia. files.wordpress.com/2013/12/libro_mineria_contraloria-2013.pdf

Luzón-Peña, Diego Manuel, Lecciones de derecho penal, Parte general ( $3^{\mathrm{a}}$ ed., Tirant lo Blanch, Valencia, 2016).

Martínez-Ortiz, Astrid (dir.), Minería y medio ambiente en Colombia (Centro de Investigación Económica y Social, Fedesarrollo, Sector de Minería a Gran Escala, SMGE, Bogotá, 2014). Disponible en: http://www.fedesarrollo.org.co/wpcontent/uploads/Fedesarrollo-Informe-Miner\%C3\%ADa-y-medio-Ambientefinal-final-final-080714.pdf

Matellanes-Rodríguez, Nuria, Derecho penal del medio ambiente (Iustel, Madrid, 2008).

Mendo-Estrella, Álvaro, El delito ecológico del artículo 325.1 del Código Penal (Tirant lo Blanch, Valencia, 2009).

Ministerio de Minas y Energía, Política minera de Colombia. Bases para la minería del futuro (República de Colombia, Bogotá, 2016). Disponible en: https://www. minminas.gov.co/documents/10180/698204/Pol\%C3\%ADtica+Minera+de+Col ombia+final.pdf/c7b3fcad-76da-41ca-8b11-2b82c0671320

Muñoz-Conde, Francisco; López-Peregrín, María Carmen \& García-Álvarez, Pastora, Manual de derecho penal medioambiental (2 ${ }^{\mathrm{a}}$ ed., Tirant lo Blanch, 2015).

Ramírez-Bastidas, Yesid, El delito ecológico (Ediciones Doctrina y Ley, Bogotá, 2007).

Roxin, Claus, Derecho penal, Parte general, II (Madrid, Civitas, 1997).

Tiedemann, Klaus, Derecho penal y nuevas formas de criminalidad (Grijley, Lima, 2007).

Velásquez-Velásquez, Fernando, Derecho penal, Parte general (4a ed., Comlibros, Bogotá, 2010).

Velásquez-Velásquez, Fernando, Manual de derecho penal, Parte general (4a ed., Ediciones Jurídicas Andrés Morales, Bogotá, 2010).

Zaffaroni, Eugenio, Manual de derecho penal, Parte general (Ediar/Temis, Buenos Aires, 2005). 


\section{Contribución en obras colectivas}

Alonso-Álamo, Mercedes, La aporía del Derecho penal del medio ambiente, en Estudios de Derecho ambiental. Libro homenaje al profesor Josep Miquel Prats-Canut, 2140 (Gonzalo Quintero-Olivares \& Fermín Morales-Prats, coords., Tirant lo Blanch, Valencia, 2008).

Centro de Investigación y Educación Popular, CINEP, Programa por la Paz, Impactos socioterritoriales de la explotación minera en los departamentos del Cesar y La Guajira, en La minería de carbón a gran escala en Colombia: impactos económicos, sociales, laborales, ambientales y territoriales, 45-68 (Friedrich-Ebert-Stiftung, FES, Bogotá, 2014). Disponible en: http://library.fes.de/pdf-files/bueros/ kolumbien/11067.pdf

Galeano-Rey, Juan \& Montañez-Ruiz, Julio, Delitos contra el medio ambiente y los recursos naturales, en Manual de Derecho penal, Parte Especial, II, 475-507 (Carlos Guillermo Castro-Cuenca, coord., Temis, Bogotá, 2011).

González-Aldana, Blanca María \& Morales-Sierra, Juan Alejandro, Normatividad penal y minería sin el cumplimiento de los requisitos legales, en Minería en Colombia: Daños ecológicos y socio-económicos y consideraciones sobre un modelo minero alternativo, 449-491 (Contraloría General de la Nación, Bogotá, 2014). Disponible en: https://justiciaambientalcolombia.org/2014/08/11/mineriacolombia-danos-eco-socio-economicos-y-modelo-alternativo/

Hawkins, Daniel, El carbón y el trabajo en Colombia: a la sombra de la locomotora minera, en La minería de carbón a gran escala en Colombia: impactos económicos, sociales, laborales, ambientales y territoriales, 23-44 (Friedrich-Ebert-Stiftung, FES, Bogotá, 2014). Disponible en: http://library.fes.de/pdf-files/bueros/ kolumbien/11067.pdf

Hormazábal-Malarée, Hernán, El principio de lesividad y el delito ecológico, en El nuevo derecho penal español. Estudios penales en memoria del profesor José Manuel Valle-Muñiz, 1417-1428 (Gonzalo Quintero-Olivares \& Fermín Morales-Prats, coords., Aranzadi, Navarra, 2001).

Iglesias-Skulj, Agustina, La protección de la ordenación del territorio, el patrimonio histórico y el medio ambiente en la sociedad del riesgo, en Ordenación del territorio, patrimonio histórico y medio ambiente en el Código Penal y la legislación especial, 19-34 (Patricia Faraldo-Cabana, dir., Tirant lo Blanch, Valencia, 2011).

Jorge-Barreiro, Agustín, El bien jurídico protegido en los delitos contra el medio ambiente en el CP de 1995, en Estudios sobre la protección penal del medio ambiente en el ordenamiento jurídico español, 1-72 (Agustín Jorge-Barreiro, Comares, Granada, 2004).

Martínez-Buján, Carlos, Derecho penal económico y de la empresa, Parte especial (5 ed., Tirant lo Blanch, Valencia, 2015).

Martínez-Buján, Carlos, Lección XXXII, Delitos relativos a la ordenación del territorio y el urbanismo, la protección del patrimonio histórico y del medio ambiente, en Derecho penal, Parte Especial, 545-566 (José Luis GonzÁlez-Cussac, coord., Tirant lo Blanch, Valencia, 2016).

Negrete-Montes, Rodrigo E., Derechos, minería y conflictos. Aspectos normativos, 
en Minería en Colombia: derechos, políticas públicas y gobernanza, 23-56 (LuIs Jorge Garay-Salamanca, dir., Contraloría General de la República, Bogotá, 2013). Disponible en: https://redjusticiaambientalcolombia.files.wordpress. com/2013/12/libro_mineria_contraloria-2013.pdf

Paredes-Castañón, José Manuel, Derecho penal español del medioambiente: una evaluación crítica, en Libro homenaje al profesor Luis Rodríguez Ramos, 751-770 (Francisco Javier Álvarez-García, Miguel Ángel Cobos-Gómez de Linares, Pilar Gómez Pavón, Araceli Manjón-Cabeza Olmeda \& Amparo MartínezGuerra, Tirant lo Blanch, Valencia, 2013).

Rudas-Lleras, Guillermo, Notas sobre la minería de carbón a gran escala en Colombia, en La minería de carbón a gran escala en Colombia: impactos económicos, sociales, laborales, ambientales y territoriales, 5-22 (Friedrich-Ebert-Stiftung, FES, Bogotá, 2014). Disponible en: http://library.fes.de/pdf-files/bueros/ kolumbien/11067.pdf

TAYlor, PAul W., La ética del respeto a la naturaleza, en Los caminos de la ética ambiental. Una antología de textos contemporáneos, 269-288 (TERESA KWIATKOWSKA \& JORGE Issa, comps., Plazas y Valdés Editores, México, 1998).

\section{Revistas}

Barrero-CÁceres, José Daniel, La contaminación ambiental como delito de resultado, 1 Estudios en Derecho y Gobierno, 79-96 (2008).

Gómez-Vélez, Martha Isabel, Aproximación al derecho penal ambiental: ideas para su abolición, 72 Estudios de Derecho, 160, 309-329 (2015). Disponible en: https:// aprendeenlinea.udea.edu.co/revistas/index.php/red/article/view/323345/20780548

HeFENDEHL, Roland, ¿Debe ocuparse el derecho penal de riesgos futuros? Bienes jurídicos colectivos y delitos de peligro abstracto, 4 Revista Electrónica de Ciencia Penal y Criminología, 14, 1-13 (2008). Disponible en: http://criminet.ugr.es/recpc/ recpc_04-14.pdf

Rodas-Monsalve, Julio César, La protección penal del medio ambiente y la función simbólica del derecho penal, 5 Revista de Derecho Público, 149-154 (1994).

\section{Tesis}

Rojas-Escobar, Laura, Análisis politico criminal y dogmático del delito de daños en los recursos naturales en Colombia (art. 331 CP) (Tesis de maestría en Derecho Penal, Universidad EAFIT, Medellín, 2014). Disponible en: https://repository. eafit.edu.co/handle/10784/2969\#.WYjytFHyiM8

\section{Documentos, reportes, informes}

Colombia, Ministerio de Minas y Energía, Unidad de Desarrollo Minero Energética, Plan nacional para el desarrollo minero, visión al año 2019 (Ministerio de Minas y Energía, Bogotá, 2006). Disponible en: http://www.upme.gov.co/docs/ 
pndm_2019_final.pdf

\section{Tratados internacionales}

Organización de Naciones Unidas, Conferencia de las Naciones Unidas sobre el Medio Humano, A/CONF.48/14/Rev.1, Declaración de Estocolmo, 5-16 de junio de 1972. Disponible en: http://www.un.org/es/comun/docs/?symbol=A/CONF.48/14/Rev.1

Organización de Naciones Unidas, Conferencia de las Naciones Unidas sobre el Medio Ambiente y el Desarrollo, A/CONF.151/26 (Vol. I), Declaración de Río, 3-14 de junio de 1992. Disponible en: http://www.un.org/documents/ga/conf151/spanish/ aconf15126-1annex1s.htm

\section{Normativa colombiana}

Colombia, Constitución Política, versión corregida 116 Gaceta Constitucional, 20 de julio de 1991. Disponible en: http://www.secretariasenado.gov.co/senado/basedoc/ constitucion_politica_1991.html

Colombia, Decreto Ley 2811 de 1974, por el cual se dicta el Código Nacional de Recursos Naturales Renovables y de Protección al Medio Ambiente, 34.243 Diario Oficial, 18 de diciembre de 1974. Disponible en: http://www.alcaldiabogota.gov.co/sisjur/ normas/Norma1.jsp?i=1551

Colombia, Decreto 100 de 1980, por la cual se expide el nuevo Código Penal, 35.461 Diario Oficial, 20 de febrero de 1980. Disponible en: http://www.suin-juriscol. gov.co/viewDocument.asp?id=1705120

Colombia, Decreto 1713 de 2002, por el cual se reglamenta la Ley 142 de 1994, la Ley 632 de 2000 y la Ley 689 de 2001, en relación con la prestación del servicio público de aseo, y el Decreto Ley 2811 de 1974 y la Ley 99 de 1993 en relación con la Gestión Integral de Residuos Sólidos, 44.893 Diario Oficial, 7 de agosto de 2002. Disponible en: http://www.alcaldiabogota.gov.co/sisjur/normas/Norma1. jsp?i=5542

Colombia, Decreto 2191 de 2003, por el cual se adopta el glosario técnico minero, 45.273 Diario Oficial, 8 de agosto de 2003. Disponible en: http://www.alcaldiabogota. gov.co/sisjur/normas/Norma1.jsp?i=9198

Colombia, Decreto Reglamentario 2715 de 2010, por el cual se reglamenta parcialmente la Ley 1382 de 2010, 47.784 Diario Oficial, 28 de julio de 2010. Disponible en: http://www.alcaldiabogota.gov.co/sisjur/normas/Norma1.jsp?i=40043

Colombia, Ley 599 de 2000, por la cual se expide el Código Penal, 44.097 Diario Oficial, 24 de julio de 2000. Disponible en: http://www.secretariasenado.gov.co/senado/ basedoc/ley_0599_2000.html

Colombia, Ley 685 de 2001, por la cual se expide el Código de Minas y se dictan otras disposiciones, 44.545 Diario Oficial, 8 de septiembre de 2001. Disponible en: http://www.secretariasenado.gov.co/senado/basedoc/ley_0685_2001.html

Colombia, Ley 1453 de 2011, por medio de la cual se reforma el Código Penal, el 
Código de Procedimiento Penal, el Código de Infancia y Adolescencia, las reglas sobre extinción de dominio y se dictan otras disposiciones en materia de seguridad, 48.110 Diario Oficial, 24 de junio de 2011. Disponible en: http://www. secretariasenado.gov.co/senado/basedoc/ley_1453_2011.html

Colombia, Proyecto de Ley 164 de 2010, Senado, por medio de la cual se reforma el Código Penal, el Código de Procedimiento Penal, el Código de Infancia y Adolescencia, las reglas sobre Extinción de Dominio y se dictan otras disposiciones en materia de seguridad, 737 Gaceta del Congreso, 5 de octubre de 2010. Disponible en: http://www.imprenta.gov.co/gacetap/gaceta.indice?v_num=737\&v_anog=2010

\section{Jurisprudencia colombiana}

Colombia, Corte Constitucional, Sentencia C-495-96, 26 de septiembre de 1996, magistrado ponente Fabio Morón-Díaz. Disponible en: http://www. corteconstitucional.gov.co/relatoria/1996/C-495-96.htm

Colombia, Corte Constitucional, Sentencia C-133-99, 3 de marzo de 1999, magistrado ponente Carlos Gaviria-Díaz. Disponible en: http://www.corteconstitucional. gov.co/relatoria/1999/C-133-99.htm

Colombia, Corte Constitucional, Sentencia C-559-99, 4 de agosto de 1999, magistrado ponente Alejandro Martínez-Caballero. Disponible en: http://www. corteconstitucional.gov.co/relatoria/1999/c-559-99.htm

Colombia, Corte Constitucional, Sentencia C-238-05, 15 de marzo de 2005, magistrado ponente Jaime Araujo-Rentería. Disponible en: http://www.corteconstitucional. gov.co/relatoria/2005/c-238-05.htm

Colombia, Corte Constitucional, Sentencia C-366-11, 11 de mayo de 2011, magistrado ponente Luis Ernesto Vargas-Silva. http://www.corteconstitucional.gov.co/ relatoria/2011/c-366-11.htm

Colombia, Corte Constitucional, Sentencia C-191-16, 20 de abril de 2016, magistrado ponente Alejandro Linares-Cantillo. http://www.corteconstitucional.gov.co/ relatoria/2016/c-191-16.htm

Colombia, Corte Constitucional, Sentencia C-389-16, 27 de julio de 2016, magistrada ponente María Victoria Calle-Correa. Disponible en: http://www. corteconstitucional.gov.co/relatoria/2016/C-389-16.htm

Colombia, Corte Constitucional, Sentencia SU132-13, 13 de marzo de 2013, magistrado ponente Alexei Julio-Estrada. Disponible en: http://www.corteconstitucional. gov.co/relatoria/2013/su132-13.htm

Colombia, Corte Suprema de Justicia, Sala de Casación Penal, Proceso 23286, 19 de febrero de 2007, magistrado ponente Mauro Solarte-Portilla.

Colombia, Corte Suprema de Justicia, Sala de Casación Penal, Proceso 27035, 15 de mayo de 2008, magistrado ponente Javier Zapata-Ortiz.

Colombia, Corte Suprema de Justicia, Sala de Casación Penal, Proceso 47504, 1 de junio de 2016, magistrado ponente Gustavo Enrique Malo-Fernández. 


\section{Direcciones web, comunicados de prensa}

Ministerio de Ambiente y Desarrollo Sostenible, Nueva estrategia contra minería criminal es un paso fundamental en la lucha contra este flagelo: Ministro Vallejo (31 de julio de 2015). Disponible en: http://www.minambiente.gov.co/index.php/ component/content/article?id=1942:nueva-estrategia-contra-mineria-criminales-un-paso-fundamental-en-la-lucha-contra-este-flagelo-ministro-vallejo 